\title{
Distintas Perspectivas do Processo de Ensino-Aprendizagem da Língua Escrita e a Formação do Alfabetizador
}

\author{
Carmen Sá Brito Sigwalt \& Sandra Regina Kirchner Guimarães \\ Universidade Federal do Paraná, Curitiba, Brasil
}

\begin{abstract}
RESUMO
Estudo teórico que analisa as diferentes perspectivas de aquisição da linguagem escrita: tradicional, construtivista psicogenética, métodos fônicos e letramento. $\mathrm{O}$ referencial de análise é a concepção de alfabetizar letrando, na qual a alfabetização (domínio do sistema gráfico) e o letramento (uso da leitura e da escrita nas diversas funções sociais) são trabalhadas conjuntamente. Uma segunda análise destaca três momentos da formação de alfabetizadores: o tradicional, o construtivista e a tentativa de superação destas duas abordagens. Os resultados do estudo evidenciaram o afastamento das diversas perspectivas metodológicas da concepção de alfabetizar letrando e a necessidade da formação de alfabetizadores considerar a alfabetização e o letramento como ações indissociáveis.
\end{abstract}

Palavras-chave: alfabetização; aquisição da linguagem escrita; formação docente.

\section{ABSTRACT \\ Different Perspectives of the Teaching-Learning Process of the Written Language and the Literacy Teacher Training}

\begin{abstract}
A theoretical study which analyses the different perspectives of the acquisition of written language: the traditional method, the psycogenetic constructivism, the phonic methods and the whole language approach. The parameter for analysis is the assumption of literacy through the whole language approach in which learning to read and write (mastering the graphic system) and literacy (appropriate use of reading and writing in different social functions) are developed together. A second analysis points out three moments in the preparation of teachers: the traditional, the constructivist and finally the attempt to overcome these two perspectives. The results of the study point out that there is a gap between these three methodological perspectives and the notion of preparing teachers who consider that mastering the graphic system and becoming competent users of language in its several social functions are inseparable teaching actions.
\end{abstract}

Keywords: literacy; acquisition of written language; teacher training.

Cabe à educação o papel de preservação e transmissão das formas de vida humana, ou seja, da cultura, na nossa sociedade, caracterizada pela forma escrita de registros culturais, assim, a aprendizagem da leitura e da escrita assume preponderante significado. No entanto os dados de rendimento escolar divulgados pelo Sistema Brasileiro de Ensino Básico (SAEB) não apresentam um nível satisfatório dos alunos no domínio da leitura e da escrita na sua língua materna, ou seja, são limitados na capacidade de leitura e interpretação de textos escritos. Os alunos terminam a quarta série com um nível crítico de desempenho nessa área de conhecimento, ficando muito distantes das habilidades que deveriam desenvolver ao final deste período de escolarização. Tais resultados nos levam a indagar: não estaria a escola brasileira atrelada a perspectivas metodológicas de ensino-aprendizagem da leitura e da escrita que têm dificultado a apropriação destes instrumentos básicos (leitura e escrita) a todos os alunos?

Acredita-se que a adoção de uma perspectiva que busque a alfabetização - aquisição da tecnologia do saber ler e escrever - e o letramento - uso efetivo do ler e do escrever em suas diferentes funções sociais de 
todos os alunos brasileiros poderá vir a contribuir, dentro dos limites impostos pelo modo de produção atual, para a construção de uma nova sociedade. Como afirma Faraco (2012, p. 82) após destacar os dados insatisfatórios de rendimento em língua portuguesa: "Não conseguimos ainda, portanto, renovar nosso sistema de língua materna; falta-nos criar uma pedagogia capaz de responder efetivamente à demanda da educação letradora democrática" (p. 82).

Parte-se do princípio que dominar a dimensão gráfica e significativa pressupõe não apenas saber grafar corretamente as palavras, mas saber usá-las em textos respeitando o seu valor semântico, o comportamento sintático e o seu uso de acordo com a situação. Em outras palavras o eixo significativo envolve as dimensões semântica, sintática e pragmática. A dimensão semântica é a relação das palavras com os objetos, coisas ou pessoas; a sintática é a relação que as palavras mantêm entre si e a pragmática é a relação das palavras com seus usuários. As três dimensões se complementam tanto na escrita como na oralidade. Os componentes sintáticos, semânticos e pragmáticos se encontram integrados de modo indissociável na realização concreta da língua (falada ou escrita).

Conforme Bakhtin (1929/1992), a utilização da língua se dá em forma de enunciados concretos (orais ou escritos) proferidos por sujeitos concretos em situações especificas. Em suas palavras

[...] a verdadeira substância da língua não é constituída por um sistema abstrato de formas linguísticas, nem pela enunciação monológica isolada, nem pelo ato psicofisiológico da sua produção, mas pelo fenômeno social da interação verbal, realizado através da enunciação ou das enunciações. A interação verbal constitui assim a realidade fundamental da língua (p. 123).

A partir destas considerações entende-se que saber ler não é apenas uma questão de deciframento de um código, mas envolve a possibilidade de compreensão textual. Saber escrever não se restringe a grafar palavras descontextualizadas, mas saber expressar ideias o que exige além de correção gramatical a capacidade de estabelecer ligação de sentido que tornem o texto compreensível e que expressem um contexto onde a linguagem escrita esteja apoiada na interação verbal, revelando sua natureza social e viva. Assim o código é utilizado na interlocução, nas relações sociais que o constituem. A leitura e a escrita não podem ser vazias de conteúdo, significado e sentido. O seu ensino e a sua aprendizagem devem estar atrelados a situações reais de uso.
Este estudo tem como problema de investigação as seguintes questões: o referencial teórico metodológico proposto pelas quatro grandes abordagens de aquisição da linguagem escrita (tradicional, construtivista psicogenética, metodologia fônica e letramento) destacam a necessidade de alfabetizar letrando? Como as propostas de formação de alfabetizadores consideram este pressuposto?

A investigação foi baseada na análise dos pressupostos teórico-metodológicos das visões tradicional, construtivista psicogenética, dos métodos fônicos e letramento. Destacam-se os fundamentos da concepção de alfabetizar letrando para explicitar a aproximação ou distanciamento das quatro perspectivas metodológicas com esta concepção. A análise da formação docente buscou verificar como se deu a preparação dos alfabetizadores nas chamadas escolas normais da época tradicional, quais os pressupostos construtivistas defendido pelo PROFA (Programa de Formação de Alfabetizadores) lançado pelo MEC (Ministério da Educação e Cultura) em 2001 e a tentativa de superação destas abordagens por meio do Programa PróLetramento lançado em 2007.

Tomou-se como hipótese que há a ênfase em uma dimensão em detrimento de outra nas concepções metodológicas presentes na escola brasileira contemporânea. Algumas supervalorizam o domínio do sistema gráfico - alfabetização considerada restrita porque enfatiza apenas uma dimensão do ensino da língua -; outras privilegiam a dimensão significativa secundarizando o domínio sistemático da grafia.

No que se refere ao método do estudo realizado, destaca-se que se tinha como pressuposto (referencial de análise) que o processo de ensino-aprendizagem inicial da escrita deve contemplar tanto o domínio do sistema gráfico quanto o uso da leitura e da escrita nas diferentes funções sociais. Neste sentido, o objeto teórico tratado foi a análise da concepção de linguagem escrita subjacente a cada uma das perspectivas analisadas e consequentemente a concepção de ensino-aprendizagem da língua que veiculam. Estas análises e reflexões são complementadas com a identificação dos referenciais teóricos que sustentam os diferentes momentos da formação de alfabetizadores. Por último, a partir das analises realizadas, busca-se identificar a aproximação ou o distanciamento entre as perspectivas analisadas e a perspectiva defendida neste trabalho, o alfabetizar letrando, a qual integra várias dimensões do aprender a ler e escrever. 


\section{OS MÉTODOS TRADICIONAIS}

Estes métodos embora tenham se apresentado com roupagens diferentes no decorrer da história da humanidade, sempre privilegiaram o domínio do sistema gráfico em detrimento do domínio da linguagem escrita em seu sentido mais amplo. No Brasil diversos autores apontam os limites dos denominados métodos tradicionais de alfabetização como Barbosa (1994), Kato (1999), Soares (2006), Klein (2006), Morais (2006), Mortati (2008), Cavazotti (2009), Rossler, Pan e Bagatin (2011).

Esta forma de ensino da língua que privilegia o código em detrimento do significado já era condenada por Comênio (1985), no início do século XVII, quando em sua obra Didática Magna - A Arte de Ensinar Tudo a Todos, ao referir-se ao método para ensinar a língua afirmava “... as palavras não se devem aprender separadamente das coisas, uma vez que as coisas separadas das palavras nem existem, nem se entendem; mas, enquanto estão unidas, existem aqui ou além e desempenham esta ou aquela função" (p. 332). O mesmo autor, ao referir-se à metodologia do ensino da língua, faz referência a não separação entre o ensinar a ler e escrever, pronunciando que "todas as línguas devem aprender-se mais com a prática que por meio de regras. Isto é, ouvindo, lendo, relendo, transcrevendo, tentando a imitação com a mão e a língua, o mais frequentemente possível" (p. 334).

Pode-se afirmar que não foi esta postura que marcou a história da aquisição do ler e do escrever. $\mathrm{Na}$ grande maioria das escolas a leitura é "imposta à criança como uma ginástica de decifração [...] e ela desaparece junto com a escola. $\mathrm{O}$ adulto não lê, não lê mais" (Bellenger, 1979, p. 58). Esta situação é identificada em diferentes países e/ou contextos sociais. Bettelheim já em 1981 afirmava, em sua obra Psicanálise da Alfabetização, que nos Estados Unidos, um país de pessoas alfabetizadas, há enorme contradição, pois embora as pessoas tenham domínio da linguagem escrita, poucos são, de fato, leitores e escritores. No Brasil o mesmo problema é apontado por autores como Oliveira (1992), Ribeiro (1999), Ribeiro, Vóvio e Moura (2002), Moreira (2003), Santos (2003) e Oliveira e Vóvio (2003).

As primeiras abordagens metodológicas para o ensino da leitura e escrita, nas escolas brasileiras, tinham uma ênfase sintética, ou seja, partiam de unidades menores para se chegar ao todo. O caminho era lento e penoso, partindo do nome das letras ou dos sons correspondentes às letras para depois apresentar as sílabas que exigiam um trabalho mnemônico e repetitivo, para só mais tarde chegar às palavras e frases. Acreditava-se que o processo deveria partir do mais simples, das unidades menores que seriam, portanto, mais fáceis de compreensão pela criança até chegar às unidades maiores e, portanto, mais complexas, segundo os pressupostos teóricos associacionistas que o sustentavam. As atividades de escrita estavam limitadas a exercícios de caligrafia e ortografia, cópias e ditados de palavras e construção de frases com palavras dadas. Estas metodologias eram acompanhadas com cartilhas de apoio didático que reproduziam o processo repetitivo de letras e padrões silábicos. Kato (1999, p. 19 e 20), ao analisar criticamente os métodos de alfabetização registra que "[...] muito do insucesso escolar poderia ser evitado se, em lugar da obsessão pelo "método", a escola procura-se ser um verdadeiro laboratório de observação do que ocorre no processo de aprendizagem".

Segundo Mortattti (2000) as formas tradicionais de alfabetização nas versões sintéticas, analíticas e analítico-sintéticas ou ecléticas estavam centradas no desenvolvimento das habilidades de codificação e decodificação. A abordagem sintética tem suas bases nas teorias associacionistas que privilegiam a questão do método de ensino entendendo que qualquer aprendizagem é garantida pela sua programação. Os métodos de orientação analítica se fundamentam especialmente na Teoria da Gestalt. O aluno primeiro deveria ser capaz de perceber globalmente cada elemento significativo, para só mais tarde ser conduzido para as unidades mínimas que constituem esses elementos significativos. As duas abordagens têm posições distintas quanto às operações básicas que envolvem a síntese e a análise, mas ambas destacam a necessidade de se estabelecer uma correspondência entre os elementos sonoros e gráficos da língua para que se realize a leitura e a escrita.

Os métodos tradicionais enfatizam os chamados pré-requisitos para a alfabetização a serem desenvolvidos na pré-escola ou período preparatório que deveria anteceder o início da alfabetização na, então chamada, escola primária. Esta perspectiva partia do pressuposto de que a dificuldade na alfabetização estava relacionada à ausência de pré-requisitos necessários ao domínio do ler e do escrever. A ênfase das atividades deste período estava relacionada às tarefas de coordenação motora, discriminação auditiva e visual, relação espaço-temporal, percepção corporal, etc.

O trabalho pedagógico da alfabetização através dos métodos tradicionais caminha paralelamente com os 
estudos dos processos psicológicos necessários como pré-requisitos para a alfabetização (percepção do esquema corporal, estruturação espacial e temporal, discriminação visual e auditiva, coordenação motora, etc.) e suas relações com os aspectos fisiológicos e neurológicos. Soares (2006), ao apontar os limites dos métodos tradicionais de alfabetização destaca que “[...] uma concepção associacionista do processo de aquisição da escrita considera o método fator determinante da aprendizagem, já que seria por intermédio da exercitação de habilidades hierarquicamente ordenadas que a criança aprenderia a ler e escrever" (p. 89).

$\mathrm{Na}$ visão tradicional o conhecimento do momento adequado para a determinação do início do processo de alfabetização foi uma polêmica entre os educadores, desde Lourenço Filho. Tal abordagem levou à utilização de testes de prontidão para se avaliarem as condições de a criança se iniciar ou não no processo de alfabetização. Alguns métodos, inclusive, enfatizaram a necessidade da aplicação desses testes para detectar o nível intelectual e de maturidade das funções específicas consideradas como pré-requisitos para o início do processo de aquisição da linguagem escrita.

Lourenço Filho (1952), na introdução do teste $\mathrm{ABC}$, faz um retrospecto histórico desse processo e defende a aplicação desses testes como a possibilidade de assegurar a eficácia do trabalho pedagógico, adequando o ensino às características do aluno e evitando-se o desperdício de esforços que representava ensinar a ler e escrever as crianças que não demonstravam maturidade para tal. As aptidões mais avaliadas por estes testes referem-se à discriminação visual e auditiva, à coordenação viso-motora e à compreensão da linguagem oral.

Os encaminhamentos metodológicos tradicionais privilegiam o trabalho com "textos" que são, de fato, conjunto de frases, muitas vezes, sem nenhum significado. O critério que norteia a escolha desses textos é a incidência de uma determinada letra ou padrão silábico. A partir da leitura destes "textos" de cartilha, as crianças são submetidas de forma sistemática a uma série de exercícios que as distanciam progressivamente da real noção de texto, ou seja, aquilo que tem significado. As cartilhas apresentam sílabas isoladas, palavras descontextualizadas e frases estranhas. Em todas as cartilhas, a leitura está sempre presa a determinado padrão silábico. Existe apenas um treinamento mecânico de estruturas elaboradas com critérios questionáveis de dificuldades. Estes pseudotextos acabam gerando pseudoescritas. As produções escritas das classes de alfabetização, submetidas a este tipo de encaminhamento, acabam sendo muito semelhantes às produções das cartilhas. Estes "textos", sem nenhum sentido, que podem ser chamados de pretextos para a apresentação de uma determinada letra ou sílaba, não comunicam uma ideia, e não utilizam recursos que a linguagem escrita possui para evitar a repetição, a redundância, etc. Klein (2010) ao abordar a questão dos métodos tradicionais afirma que é fundamental “[...] uma crítica necessária e acertada à alfabetização tradicional que descurava qualquer tratamento da textualidade, centrando-se exclusivamente no ensino fragmentado e mecanicista - do código" (p. 1). A concepção de linguagem que está presente na maioria dos métodos tradicionais de alfabetização vê a língua como um conjunto de formas prontas e acabadas que devem ser aprendidas. Por isso, o encaminhamento pedagógico destes métodos no tocante ao processo de alfabetização supervaloriza o domínio do sistema gráfico, secundarizando o trabalho da linguagem no seu sentido mais amplo, que é o trabalho com o significado, com o sentido.

Embora se assentem em diferentes formas de encarar a origem do conhecimento, os métodos tradicionais de alfabetização consideram o aprendiz alguém que antes de frequentar as séries escolares de alfabetização não tem conhecimento e experiências sobre a língua, aprende recebendo e memorizando informações prontas sobre letras, sílabas e palavras, dadas pelo professor. Apoia-se na repetição (fixação) como processo cognitivo principal na garantia da aprendizagem, que ocorre sem haver, necessariamente, uma compreensão da relação entre os elementos que estruturam a língua. A alfabetização é vista como a aquisição de um código fundado na relação entre fonemas e grafemas. A concepção de língua é de que é um código a ser decifrado e codificado, predominando a prática mecânica de memorização da grafia correta das palavras. A leitura é descontextualizada, uma vez que a linguagem é distanciada de seu uso real e de sua função principal, a interação entre as pessoas.

\section{A PSICOGÊNESE DA LÍNGUA ESCRITA}

No Brasil, a partir da metade da década de 1980 , em oposição às metodologias que tratavam do trabalho de alfabetização dentro da perspectiva que ficou conhecida no sistema educacional como "tradicional" começa a tomar corpo uma nova proposta para o trabalho pedagógico de aprendizagem da leitura e da escrita que teve seus fundamentos baseados, principalmente, nos estudos das pesquisadoras Emilia Fer- 
reiro e Ana Teberosky (Los Sistemas de Escritura en el Desarollo del Niño, publicado 1979 e editado no Brasil com o título de Psicogênese da Língua Escrita, em 1985).

Conforme Ferreiro, esse processo se concretiza, basicamente, em três grandes períodos. O primeiro período caracteriza-se pela distinção entre modo de representação figurativo e o não-figurativo, ou seja, a criança é capaz de fazer a distinção entre 'desenhar' e 'escrever', começa a utilizar sinais gráficos diversos (linhas, bolinhas, letras e números) com determinada repetição para representar à escrita. No segundo período verifica-se a construção de formas de diferenciação entre os sinais gráficos que se manifestam pelo controle progressivo das variações, tanto sob um eixo quantitativo (a criança estabelece quantidades diferentes de grafias para representar diferentes palavras), como sob um eixo qualitativo (a criança varia o repertório e a posição das grafias para obter escritas diferentes). Estas variações realizadas neste período correspondem à fase pré-silábica, sendo que uma das características da escrita é a correspondência da quantidade dos sinais gráficos mais com o tamanho do objeto do que com os sons da fala. No terceiro período verifica-se a fonetização da escrita pela atenção que a criança começa a dar as propriedades sonoras do significante, ou seja, dá-se a descoberta de que as partes da escrita (letras) podem corresponder a outras tantas partes da palavra. Emília Ferreiro distingue três fases neste período:

- Fase silábica: a criança formula a hipótese de que cada sílaba deve corresponder a uma letra. Começa a se esboçar a necessidade de uma certa ordem das letras na palavra. Dá-se o início do entendimento da vinculação leitura/escrita até então independentes; aos poucos, a criança usa as mesmas letras para representar os mesmos sons.

- Fase silábico-alfabética: a criança descobre que a sílaba não é uma unidade, mas pode ser reanalisável em elementos menores. Esta descoberta dá-se a partir dos conflitos que a criança experimenta na fase silábica; como por exemplo, a escrita de monossílabos. Isso porque, pelas suas descobertas anteriores, uma única letra não basta para representar uma palavra. Um outro conflito dá-se pelo contato e atenção maior que a criança passa a dar à escrita dos adultos, na qual verifica sempre um maior número de letras para cada palavra do que aquele que suas hipóteses consideravam necessário.

- Fase alfabética: verifica-se aqui a estruturação dos vários elementos que compõem o sistema de es- crita. A criança distingue algumas unidades linguísticas: letras, sílabas e frases. Ler e escrever assumem seus papéis de ações inversas uma da outra, o que antes podia ser ignorado ou omitido. A criança faz aqui a correspondência precisa de uma letra para cada fonema da palavra. Passa, portanto, a escrever alfabeticamente. Todavia, a conquista deste nível não significa ainda saber grafar corretamente, pois a criança, aqui, limita-se a ouvir a pronúncia de cada som da fala e a colocar letras que lhe correspondam, por exemplo, qopo (por copo) e xinelo (por chinelo), etc. Resta agora percorrer o caminho que a levará a consolidar seu domínio sobre o sistema gráfico da nossa língua.

Observa-se, assim, que os estudos de Ferreiro explicam os diferentes níveis de conceptualização pelos quais a criança passa ao construir seu conhecimento sobre a escrita.

As diferentes propostas que surgem a partir da década de 1980, embora com algumas diferenças na sua aparência, tiveram na sua essência um mesmo pressuposto teórico, ou seja, a premissa de que o sujeito que aprende a língua escrita passa por um processo ativo de construção de hipóteses sobre a estrutura da língua em que deixa de ser um mero receptor de um ensino baseado fundamentalmente na figura de um professor que ensina para uma nova concepção, onde o suporte básico está sustentado na perspectiva de que existe um aluno que aprende e que esta aprendizagem se dá através de um processo construtivo. É importante ressaltar que esta perspectiva teórica chega ao Brasil num momento em que uma parcela significativa da população escolarizada não conseguia sucesso no denominado processo de alfabetização tradicional e ao lado deste indicativo tínhamos uma sociedade marcada por um grande contingente de sujeitos não alfabetizados, por isso a tendência de encontrar soluções "milagrosas" era bastante tentadora. É neste contexto que a socialização dos estudos de Emilia Ferreiro ganha destaque e diferentes interpretações de sua teoria resultaram em propostas metodológicas algumas vezes equivocadas.

O construtivismo que se identifica na psicogênese da língua escrita focaliza como o aluno (alfabetizando) aprende, o qual é visto como sujeito da aprendizagem, que só aprende a língua escrita, elaborando hipóteses e estratégias sobre ela. Portanto, Ferreiro e Teberosky (1985) e Ferreiro nas obras Alfabetização em Processo (2001) e Reflexões sobre Alfabetização (1996) concebem a escrita como objeto de conhecimento do aprendiz e o professor assume o papel de mediador, orientador, coordenador, problematizador, 
que organiza atividades que favorecem a reflexão sobre a escrita e a evolução das concepções do aprendiz. Apoia-se na capacidade do aprendiz refletir, inferir, estabelecer relações, processar e compreender informações transformando-as. A concepção de aprendizagem é baseada na compreensão, no estabelecimento de relações. A alfabetização é vista como processo de construção conceitual, contínuo, iniciado muito antes de o aluno ir para a escola e que se desenvolve, simultaneamente, dentro e fora da sala de aula. Portanto, o processo de alfabetização pressupõe construção de conhecimento, mais especificamente a compreensão do sistema de escrita.

É importante salientar ainda que de acordo com esta perspectiva teórica a língua é concebida como sistema de representação, como um objeto de conhecimento construído socialmente. $\mathrm{O}$ aprendizado do sistema de escrita é concebido como resultado de processo ativo no qual o sujeito da aprendizagem, desde os seus primeiros contatos com a escrita, constrói e reconstrói hipóteses sobre a natureza e o funcionamento da língua escrita. O texto é indicado como núcleo do trabalho com a língua e os erros cometidos pelos alunos durante o processo são vistos como tentativas de acerto sendo considerado construtivo.

As didatizações apoiadas na teoria da psicogênese da escrita demonstram limites na articulação das dimensões do alfabetizar e letrar. Ao enfatizarem a construção do conhecimento pelo aluno, aguardam que o domínio do sistema gráfico, o alfabetizar aconteça em decorrência do contato do aluno com textos. Assim percebe-se nas propostas construtivistas um distanciamento do pressuposto de alfabetizar-letrando. Ao supervalorizar a dimensão significativa caem num equívoco de acreditar numa aprendizagem espontânea da escrita alfabética, do alfabetizar.

\section{OS MÉTODOS FÔNICOS}

João Batista Araújo e Oliveira (2007), um dos maiores defensores do método fônico no Brasil, afirma que a capacidade de decodificar e de codificar são conceitos centrais da alfabetização e diz que:

[...] alfabetizar significa ensinar o alfabeto, dar ao aluno os elementos para ele descobrir como funciona esse código, como decodificar fonemas em grafemas e vice-versa. A decodificação permite formar um leitor autônomo, capaz de ler qualquer palavra. Mas a alfabetização requer mais do que simplesmente alfabetizar (p. 18).
Fica evidente na citação de Oliveira que o domínio do código gráfico e suas relações com os diversos fonemas é a primeira etapa do processo de alfabetização, embora este processo não se restrinja ao domínio das relações entre grafemas e fonemas. Para Oliveira, a decodificação constitui a primeira etapa do processo de alfabetizar e só será possível "compreender" num segundo momento. Há uma clara dissociação entre dominar o gráfico e compreender o significado. Oliveira (2007, p. 20) ao diferenciar aprender a ler e ler para aprender destaca:

$\mathrm{Na}$ etapa inicial da escolarização o aluno está aprendendo a ler: a prioridade, a atenção e o esforço se concentram em quebrar, decifrar o código alfabeto, entender o que significam esses sinais que chamamos de letra impressa, que palavras eles querem representar. Esta é a etapa do aprender a ler.

A citação reafirma a concepção do autor, ou seja, primeiro "quebrar" o alfabeto em grafemas e fonemas para posteriormente trabalhar a dimensão significativa. Parece existir uma proximidade acentuada com a concepção tradicional de alfabetização que sustenta o pressuposto de que o trabalho com a dimensão gráfica deve preceder a abordagem significativa.

Oliveira (2007, p. 30), ao justificar a abordagem fonética no processo de aquisição da língua assim se pronuncia:

[...] num determinado momento da alfabetização fazse necessário tornar esses sons conscientes, já que são eles, e não as letras, que constituem as menores unidades que dão significado a uma palavra. Tomar consciência dos fonemas é essencial para compreender o princípio alfabético - e, por vez, compreender as regras do código alfabético próprias de cada língua.

O autor (p. 34) enfatiza um ensino etapista, ao afirmar que

[...] uma coisa é tocar notas, outra coisa é tocar música. Uma coisa é dar passos de balé outra dançar. O mesmo se aplica à leitura: ler para aprender requer um nível adequado de fluência. Antes disso o aluno está lendo letras - da mesma forma que o aprendiz está tocando notas ou dando seus primeiros passos de dança.

Diferentemente do postulado por Oliveira, Kato e Moreira (1997, p. 42) enfatizam a natureza social da aquisição da leitura e da escrita quando afirmam: 
Para aprender a ler e a escrever é necessário primeiramente aprender que a linguagem escrita serve de mediadora numa diversidade de atividades sócioculturais da vida cotidiana, ou aprender como participar de um conjunto de práticas socialmente organizadas que envolvem o uso de materiais escritos.

Ainda de acordo com Oliveira (2007, p. 39),

[...] a consciência dos fonemas não aparece espontaneamente, por construção mental, em consequência da simples exposição à escrita. Para desenvolver consciência fonêmica e o princípio alfabético tornase necessária a intervenção explícita do professor (ou pais), usando palavras ou sílabas simples, e não material de leitura significativa.

Fica registrado pelo autor que o ponto de partida da abordagem metodológica pode ser uma simples sílaba e não um texto significativo.

Oliveira (2007, p. 53) faz críticas à ideia de que a criança deve ser submetida a textos e contextos significativos para iniciar o processo de alfabetização. Para ele esta ideia está associada ao princípio de que o objetivo da leitura é a compreensão. Nesta perspectiva, dá-se grande importância aos usos sociais da língua, em detrimento da língua como objeto de estudo. E defende que para aprender a ler são necessários "textos adequados ao nível de compreensão e decodificação do aluno ...."

A fragmentação do processo, tal como se dá nas metodologias tradicionais, fica clara com a seguinte citação do autor (2007, p. 103):

Professor [...] para que o aluno seja alfabetizado,

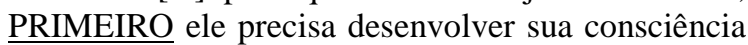
dos fonemas, dos sons. Somente mais tarde vai aprender a ler - cada coisa deve ser feita há seu tempo. Ainda não é hora de ensinar a ler ou escrever - é hora de ensinar a reconhecer como os sons funcionam para formar palavras. (grifo do autor)

A proposta dos métodos fônicos expressa, principalmente no período inicial da alfabetização, uma concepção demasiadamente artificial, mecânica e distante do sujeito a quem se aplica, ou seja, a criança. A distância entre a leitura significativa e a maneira de alfabetizar fica evidente. Ler não é apenas decifrar, corre-se o risco do aprendiz se esgotar decifrando sons de letras e sílabas. Esses elementos nada têm a ver com o sentido.

Conclui-se que os métodos fônicos, em oposição ao construtivismo, defendem que é preciso primeiro ensinar a codificar e decodificar para somente mais tarde o aluno poder efetivamente ler e escrever. Nesta perspectiva o aprendiz será inicialmente submetido a atividades que buscam a aprendizagem do sistema gráfico para num segundo momento trabalhar com diferentes textos e suas diversas funções sociais. Tal postura se afasta da concepção de alfabetizar-letrando onde se afirma que os dois processos são indissociáveis, simultâneos e interdependentes.

\section{O PROCESSO DE LETRAMENTO}

O Brasil vem vivendo desde meados dos anos 1980, paralelamente ao período de divulgação das ideias "construtivistas", um novo momento de reflexão e propostas sobre o processo de aquisição da leitura e da escrita sob o nome de letramento. Tal perspectiva enfatiza a leitura e a escrita como práticas sociais.

O termo letramento é a tradução da palavra da língua inglesa literacy, e conforme Soares (1998), vem do latim - littera - que quer dizer letra, com o sufixo $-c y$, que denota qualidade, condição, ou seja, literacy é o "estado ou condição que assume aquele que aprende a ler e escrever" (p. 17). Essa palavra criada é a união da letra - littera - com sufixo mento, que é o resultado de uma ação. Assim, segundo Soares, letramento é o "resultado da ação de ensinar ou de aprender a ler e escrever: o estado ou condição que adquire um grupo social ou um indivíduo como consequência de ter-se apropriado da escrita" (p. 18). Portanto, "letramento" pode ser concebido como a relação que o indivíduo estabelece com a língua escrita e as práticas letradas.

A palavra "letramento" começou a ser utilizada, em nosso país, nos anos de 1980 por pesquisadores das áreas de Educação e Linguística. No entanto, diferentes têm sido seus significados e objetivos. Existe uma articulação entre alfabetização e letramento embora a primeira palavra não seja pré-requisito para a segunda. A ideia central designada pelo termo "letramento" está vinculada à compreensão de que não basta a alfabetização no sentido restrito da mera decodificação e codificação da linguagem escrita, é preciso saber utilizar a leitura e a escrita de acordo com as contínuas exigências sociais.

Na segunda metade da década de 1980 aparecem, no âmbito acadêmico, as primeiras proposições da palavra "letramento" utilizada no sentido de algo superior ao simples processo de "alfabetização". Encontra-se na obra No Mundo da Escrita: Uma Perspectiva 
Psicolinguística, de Mary Kato, em 1986, considerações sobre o termo ao afirmar que a língua falada culta é consequência do letramento. Em 1988, Leda Verdiani Tfouni, no capítulo introdutório do livro: Adultos Não Alfabetizados: O Avesso do Avesso, distingue alfabetização de letramento. Segundo Soares (1998, p. 15) este é o momento em que letramento ganha estatuto de termo técnico no léxico dos campos da Educação e das Ciências Linguísticas.

Gradativamente o termo, inicialmente restrito ao mundo acadêmico, foi ganhando novos espaços, aparecendo nas propostas pedagógicas das entidades mantenedoras dos sistemas educacionais, nos projetos políticos pedagógicos das instituições de ensino, nos diálogos dos educadores, nas diferentes propostas de aquisição da língua escrita e até em títulos de materiais didáticos para crianças, jovens e adultos. $\mathrm{O}$ termo alfabetização não foi abandonado, mas ficou limitado a uma concepção mais restrita vinculada à ideia de simples domínio de um código gráfico. Nesta perspectiva o papel da escola é o de propiciar condições para que os alunos sejam expostos a diversos textos e práticas letradas, ampliando a visão dos alunos em relação à escrita e levando-os a perceberem novos usos e funções da mesma e estimulando-os a relacionarem-se cada vez mais intensamente com o mundo letrado.

Não obstante a validade da produção teórica sobre letramento no Brasil referenciada por Kato (1986), Tfouni (1988), Kleiman (1995), Soares (1998 e 2010), Terzi (2001), Mortatti (2004), entre outros, que destacam a necessidade do letramento mas não explicitam como alfabetizar, no sentido restrito de garantir o domínio sistemático da grafia da língua portuguesa que é pré-requisito indispensável para que os sujeitos possam fazer uso efetivo da leitura e da escrita. Ilustra-se o afirmado com as ideias defendidas por Terzi (2001) onde a autora explicita a dimensão política do processo de letramento e afirma ser necessário alfabetizar, no sentido de garantir ao aluno o domínio do sistema gráfico, de ser capaz de codificar e decodificar. A autora reconhece a importância do sujeito estar alfabetizado, mas faz apenas uma referência vaga em como desenvolver o processo. Nas suas palavras: “... o trabalho parte da prática social e do texto como objeto linguístico social para chegar à palavra e à sílaba, num movimento inverso ao da alfabetização tradicional ( $\mathrm{p}$. 145). Acredita-se que os professores que trabalham com o processo de aquisição da linguagem escrita necessitam de orientações mais claras e objetivas sobre como alfabetizar.
A ênfase no letramento sem uma explicação mais clara de como, efetivamente, alfabetizar não poderá contribuir para um salto qualitativo no processo de aquisição da leitura e da escrita. Percebe-se que as propostas de letramento destacam que não basta aprender a codificar e decodificar, a se apropriar do sistema de escrita, mas saber utilizar a língua em suas diferentes funções e usos sociais. Não ignoram a necessidade de se garantir o domínio sistemático do código gráfico, porém, há pouca ênfase em como garantir esse domínio se afastando da perspectiva de alfabetizar-letrando.

\section{A PERSPECTIVA DE ALFABETIZAR-LETRANDO}

Estudos recentes têm procurado unir a alfabetização e o letramento, a articulação das ações de alfabetização - aquisição da tecnologia do saber ler e escrever - com a promoção do letramento - fazer uso efetivo do ler e do escrever em suas diferentes funções sociais - buscam contribuir para que todos os alunos possam ter acesso e permanência no mundo da escrita.

Acredita-se que, no Brasil, Paulo Freire foi um dos idealizadores da proposta de "alfabetizar-letrando" num momento em que esta expressão ainda não existia. Para Paulo Freire (1987) "aprender a ler, a escrever, alfabetizar-se é, antes de mais nada, aprender a ler o mundo, compreender o seu contexto, não numa manipulação mecânica de palavras, mas numa relação dinâmica que vincula linguagem e realidade" (p. 8). Embora tenha se tornado conhecido pela criação do método de alfabetização que recebeu o seu nome, seria reducionismo considerar-se a proposta de Paulo Freire como apenas um método de alfabetização de adultos. Freire criou uma concepção de alfabetização inserida numa concepção de educação.

Entre os estudiosos atuais do processo de aquisição da leitura e da escrita que enfatizam a necessidade de alfabetizar - letrando destaca-se Magda Soares. Soares (2010, p. 15), comparando com a exigência de um passaporte, para que seja permitida a entrada em outros países, diz que também a entrada no país ou mundo da escrita exige passaporte, mas essa exigência tem uma peculiaridade: são necessários dois passaportes, não apenas um. Um passaporte é a aquisição de uma tecnologia - o sistema de escrita alfabético e ortográfico, e as convenções para seu uso, que se obtém por meio do processo de alfabetização. $\mathrm{O}$ outro passaporte é o desenvolvimento de competências para o uso dessa tecnologia em práticas sociais que envolvem a língua escrita (saber ler e escrever em diferentes situa- 
ções e contextos), que se obtém por meio do processo de letramento. Afirma que alfabetização e letramento são indissociáveis, simultâneos e interdependentes.

Diferentes autores, embora tratando de aspectos diferentes com respeito à relação entre alfabetização e letramento, chamam a atenção para a importância de se alfabetizar letrando. Albuquerque, Ferreiro e Morais (2008, p. 254) afirmam que as propostas que concebem a língua como enunciação, como discurso e não só como comunicação incluem no tratamento didático as relações da língua com aqueles que a utilizam, com o contexto no qual é utilizada, com as condições sociais e históricas de sua produção e recepção. Levando à importância de se considerar a alfabetização um processo de apropriação (reconstrução, do ponto de vista cognitivo) do sistema de escrita alfabética e a necessidade de considerá-la também como prática de letramento ou imersão na cultura escrita.

Os dias atuais exigem uma escola que seja capaz de garantir a todos os alunos o acesso ao saber elaborado. E o domínio da linguagem escrita em seu sentido amplo, que é decorrência de uma perspectiva que articula alfabetização e letramento, representa um instrumento básico, uma ferramenta fundamental para a apropriação dos conhecimentos historicamente produzidos.

\section{A FORMAÇÃO DOS ALFABETIZADORES}

O processo de formação para atuação como alfabetizador pode ser dividido em três grandes momentos. $\mathrm{O}$ primeiro denominado momento tradicional, o segundo chamado período construtivista e o terceiro numa tentativa de superação dos dois momentos anteriores que aqui se denomina de momento de superação de propostas limitadas.

No Brasil, até o final da década de 1970, o trabalho de formação inicial para a futura atuação de alfabetizadores se fazia de forma que o aluno dos cursos de preparação para o magistério - as chamadas escolas normais e regionais - dominasse os diferentes métodos de alfabetização existentes de maneira que o futuro docente pudesse, posteriormente, adotar um dos métodos estudados durante o curso ou pudesse ser levado a construir o seu próprio encaminhamento metodológico. A partir da década de 1980 tem-se a hegemonia da perspectiva construtivista. Este período é marcado pela abordagem da teoria de Emilia Ferreiro e colaboradores e pelas didáticas de alfabetização para cada nível de conceptualização da escrita. Entre as propostas de formação docente deste momento construtivista destaca-se o PROFA (Programa de Formação de Professores Alfabetizadores) coordenado pelo MEC e lançado em 2001. O Programa é composto por três módulos sendo que nos dois primeiros há uma ênfase no processo de "construção" da escrita pelos alunos. No módulo 3 esta perspectiva não está mais presente, neste módulo enfatiza-se a necessidade de um professor que, de fato, ensine. O terceiro momento de formação docente é concretizado pela suspensão da visão tradicional e construtivista e tem influência da concepção de letramento que é incorporada como contribuição significativa na superação dos níveis restritos das duas perspectivas anteriores. Assim o terceiro momento de capacitação de alfabetizadores se dá a partir do final da década de 90 e inicio dos anos 2000 com contribuições significativas de diferentes autores, como entre outros destacam-se Morais (2006), Klein (2010), Mortatti (2008), Soares (1998, 2006 e 2010), Faraco (2012) e Albuquerque, Morais e Ferreira (2008), que se debruçam sobre a problemática do ensino de língua materna e socializam suas produções através de diferentes obras que não se restringem a apenas uma das dimensões do processo, ou seja, tratar apenas do ensino tal como propuseram os metodologistas tradicionais ou abordar somente como se dá o processo de aprendizagem dos alunos conforme a concepção construtivista.

O novo paradigma de qualificação docente salienta a necessidade de uma sólida formação inicial ao mesmo tempo em que destaca a importância do processo de capacitação continuada e passa a conceber a alfabetização e o letramento, que embora tenham conceitos distintos, como ações indissociáveis - em outras palavras o docente deve ser qualificado de maneira a ser capaz de alfabetizar letrando, ou seja, ensinar a ler e escrever no contexto das práticas sociais da leitura e da escrita, de modo que os alunos se tornem, ao mesmo tempo, alfabetizados (sendo capazes de fazer uso efetivo da leitura e da escrita). Superando a estreiteza destes dois primeiros momentos de formação há que se adotar, nos cursos de formação inicial e continuada, uma concepção de língua escrita enquanto um sistema de representação, em que a grafia das palavras e seus significados estão associados, encaminhando o processo de alfabetização e letramento para além do mero domínio do sistema gráfico, propondo o efetivo domínio da linguagem escrita tomada na sua totalidade.

\section{CONCLUSÕES E CONSIDERAÇÕES FINAIS}

$\mathrm{O}$ estudo demonstrou que as perspectivas de aquisição da língua escrita: tradicional, construtivista psicogenética, métodos fônicos e letramento se afastam 
da concepção de alfabetizar letrando. Os métodos tradicionais focam sua ação apenas no domínio do sistema gráfico; a perspectiva construtivista psicogenética supervaloriza a dimensão significativa e a forma como é trabalhada pelos alfabetizadores sugere que a aprendizagem da escrita alfabética possa ocorrer de forma espontânea; o processo de letramento não ignora a necessidade de se garantir o domínio sistemático do código gráfico, porém dá pouca ênfase em como garantir este domínio e os métodos fônicos afastam o aprendiz da atividade real de ler e escrever no início da aprendizagem da língua dissociando a dimensão gráfica da significativa. Tais constatações sugerem a necessidade da construção de uma nova instituição de ensino que, efetivamente, garanta a formação de leitores e escritores, o que exige que adotem pressupostos teórico-metodológicos que busquem alfabetizar letrando. Desta forma, acredita-se que é possível que os alunos se tornem ao mesmo tempo alfabetizados, adquirindo a tecnologia do saber ler e escrever e sendo capazes de fazer uso efetivo da leitura e da escrita em suas diferentes funções sociais.

A análise da formação docente dos alfabetizadores pode ser dividida em três grandes momentos: o primeiro denominado momento tradicional; o segundo chamado momento construtivista e o terceiro representa um avanço em relação aos dois momentos anteriores, que aqui se denomina de momento de superação de propostas limitadas. O primeiro período denominado de momento tradicional ocorria, prioritariamente, nas chamadas escolas normais de nível médio. O trabalho estava centrado na apresentação de diferentes métodos de alfabetização existentes de maneira que o futuro docente pudesse, posteriormente, adotar um dos métodos estudados durante o curso ou ser levado a reconstruir o seu próprio encaminhamento metodológico a partir de várias propostas. Este momento é marcado pela ênfase no processo de ensino. $\mathrm{O}$ momento construtivista é caracterizado pela abordagem da teoria de Emilia Ferreiro e colaboradores e pelas didáticas de alfabetização para cada nível de conceptualização da escrita. Destaca-se neste momento o PROFA (2001), cujo pressuposto é de que a aprendizagem inicial da leitura e da escrita é resultado de um processo de construção do aprendiz. Este período está centrado na aprendizagem do aluno, secundarizando o processo de ensino. O terceiro momento - de superação das propostas anteriores - procura superar as visões tradicional e construtivista e concebe a alfabetização e o letramento como ações indissociáveis. $\mathrm{O}$ Programa Pró Letramento (MEC 2007) é a expressão deste período. $\mathrm{O}$ programa trata do processo de ensino e de aprendizagem como processos distintos, mas articulados formando uma unidade.

Conclui-se que uma escola letradora exige a adoção desta perspectiva na formação dos responsáveis pela aquisição da língua escrita.

\section{REFERÊNCIAS}

Albuquerque, E. B. C., Morais, A. G., \& Ferreira, A. T. B. (2008). As práticas cotidianas de alfabetização: $\mathrm{O}$ que fazem as professoras? Revista Brasileira de Educação, 13, 252-264. Retirado de http://dx.doi.org/10.1590/S1413-24782008000200005

Bakhtin, M. V. N. V. (1992). Marxismo e filosofia da linguagem (M. Lahud \& Y. F. Vieira, Trans.). São Paulo: Hacitec. (Trabalho original publicado em 1929)

Barbosa, J. J. (1994). Breve história das metodologias. In J. J. Barbosa (Ed.), Alfabetização e leitura (pp. 28-42). São Paulo: Cortez.

Bellenger, L. (1979). Os métodos de leitura (O. M. Cajado, Trans.). Rio de Janeiro: Zahar.

Bettelheim, B. (1981). Psicanálise da alfabetização (J. L. Caon, Trans.). Porto Alegre: Artes Médicas.

Cavazotti, M. A. (2009). Fundamentos teóricos e metodológicos da alfabetização. Curitiba: IESDE Brasil.

Comênio, J. A. (1985). Didática magna - Tratado de ensinar tudo a todos. Lisboa: Fundação Caloute Gulbenkian.

Faraco, C. A. (2012). Linguagem escrita e alfabetização. São Paulo: Contexto.

Ferreiro, E. (2001). Alfabetização em processo (M. N. Paro, Trans.). São Paulo: Cortez.

Ferreiro, E. (1996). Reflexões sobre alfabetização (H. Gonzales et al., Trans.). São Paulo: Cortez.

Ferreiro, E., \& Teberosky, A. (1985). Psicogênese da língua escrita. (D. M. Lichtenstein et al., Trans.). Porto Alegre: Artes Médicas.

Lourenço Filho, M. B. (1952). Testes ABC: Para a verificação da maturidade necessária à aprendizagem da leitura e escrita. São Paulo: Melhoramentos.

Freire, P. (1987). A importância do ato de ler: Em três artigos que se completam. São Paulo: Cortez.

Kato, M. (1986). No mundo da escrita: Uma perspectiva psicolinguística. São Paulo: Martins Fontes.

Kato, M. (1999). O aprendizado da leitura. São Paulo: Martins Fontes.

Klein, L. R. (2006). Alfabetização: Quem tem medo de ensinar? São Paulo: Cortez.

Klein, L. R. (2010). Alfabetização e letramento: Considerações sobre a prática pedagógica no ensino da língua. Trabalho não publicado, Universidade Federal do Paraná, Curitiba. Retirado de http://www.nupemarx.ufpr.br/Trabalhos/Artigos/KLEIN_ Ligia_Alfabetizacao_e_letramento.pdf

Kleiman, A. (Ed.) (1995). Os significados do letramento: Uma nova perspectiva sobre a prática social da escrita. Campinas: Mercado das Letras.

Ministério da Educação. Secretaria de Educação Fundamental. (2001). Programa de Formação de Professores Alfabetizado- 
res. Brasília, DF: Ministério da Educação. Secretaria de Educação Fundamental.

Ministério da Educação. (2007). Pro-Letramento: Programa de formação continuada de professores dos anos/séries iniciais do ensino fundamental: Alfabetização e linguagem. Brasília, DF: Ministério da Educação. Secretaria de Educação Fundamental.

Ministério da Educação. (2007). Resultados do SAEB (pp. 6-61). Retirado de http://www.inep.gov.br/download/saeb/2005/saeb 1995.2005.pdf.

Morais, A. G. (2006). Concepções e metodologias de alfabetização: Por que é preciso ir além da discussão sobre velhos métodos? [CD-ROM]. Anais do Encontro Nacional de Didática e Prática de Ensino (ENDIPE) - Discursos recentes sobre a alfabetização no Brasil, Recife.

Moreira, D. A. (2003). Analfabetismo funcional: O mal nosso de cada dia. São Paulo: Pioneira.

Mortatti, M. R. L. (2000). Os sentidos da alfabetização 1876/1994. São Paulo: Editora UNESP.

Mortatti, M. R. L. (2004). Educação e letramento. São Paulo: Editora UNESP.

Mortatti, M. R. L. (2008). A "querela dos métodos" de alfabetização no Brasil: Contribuições para metodizar o debate. Acolhendo a Alfabetização nos Países de Língua Portuguesa, 3, 91-114. Retirado de http://alfabetizarvirtualtextos.files.word press.com/2012/09/mortatti_quereladosmetodos1.pdf

Oliveira, J. B. A. (2007). O ABC do alfabetizador. Belo Horizonte: Alfa Educativa.

Oliveira, M. K. (1992). Analfabetos na sociedade letrada: Diferenças culturais e modos de pensamento. Travessia: Revista do Migrante, 5, 17-20.

Oliveira, M. K., \& Vóvio, C. L. (2003). Homogeneidade e heterogeneidade nas configurações do alfabetismo. In V. M. M. Ribeiro, (Ed.). Letramento no Brasil: Reflexões a partir do INAF (pp. 155-175). São Paulo: Global.
Ribeiro, V. M. (1999). Alfabetismo e atitudes. Campinas: Ação Educativa-Papirus.

Ribeiro, V. M., Vóvio, C. L., \& Moura, M. P. (2002) Letramento no Brasil: Alguns resultados do indicador nacional de alfabetismo funcional. Educação e Sociedade, 23, 49-70.

Rossler, J. H., Pan, S. M. A, \& Bagatin, T. (2011). La guerre des methodes au Brésil. Lês Actes de Lecture, 113, 7-13. Retirado de http://www.lecture.org/revues_livres/actes_lectures/AL/ AL113/al113_p25.pdf

Santos, G. L. (2003). Educação ainda que tardia: A exclusão da escola e a inserção de adultos das camadas populares em um programa de EJA. Revista Brasileira de Educação, 24, 107125. Retirado de http://www.scielo.br/pdf/rbedu/n24/n24a09. pdf

Soares, M. (1998). Letramento: Um tema em três gêneros. Belo Horizonte: Autêntica.

Soares, M. (2010). Revista Alfabetização e Letramento - Orientações pedagógicas para os anos iniciais do ensino fundamental de nove anos. Curitiba: Secretaria de Estado da Educação.

Soares, M. (2006). Alfabetização e letramento. São Paulo: Contexto.

Terzi, S. B. (2001). A experiência de letramento em Inhapi e Olho D’Água do Casado, Alagoas. Revista do Programa Alfabetização Solidária, 1, 143-153.

Tfouni, L. V. (1998). Adultos não alfabetizados: O avesso do avesso. Campinas: Pontes. 